\title{
Granulomatosis with polyangiitis, a new nomenclature for Wegener's Granulomatosis - Case report*
}

\author{
Alexandre Moretti de Lima ${ }^{1}$ \\ Sheila Pereira da Rocha ${ }^{2}$ \\ Fabio Humberto Ribeiro Paes Ferraz ${ }^{3}$
}

\author{
Pedro de Freitas Silva Torraca ${ }^{1}$ \\ Carmelia Matos Reis Santiago ${ }^{3}$
}

DOI: http:/ / dx.doi.org/10.1590/abd1806-4841.20153455

\begin{abstract}
A bstract: The granulomatosis with polyangiitis, initially known as Wegener's granulomatosis, is a small and medium vessels vasculitis. It's classic form presents a triad: necrotizing granuloma of respiratory tract, necrotizing cutaneous vasculitis and glomerulonephritis. This vasculitis has cytoplasmic antineutrophil antibodies as signal. This work illustrates a case, of multisystemic rare disease, in which the segment and treatment were considered satisfactory for symptoms remission.
\end{abstract}

Keywords: Anti-neutrophil cytoplasmic antibody-associated vasculitis; Granulomatosis with Polyangiitis; Vasculitis

\section{INTRODUCTION}

Initially described by Klinger in 1931 and by Wegener in 1936, Wegener's granulomatosis is a small and medium vessels vasculitis. ${ }^{1,2}$ After 2012, with the advent of a new Chapel Hill Consensus Conference (CHCC 2012), it was renamed granulomatosis with polyangiitis (GP). ${ }^{3}$

With an unknown etiology, GP is a rare multisystem disease, with no gender preferences, common in Caucasians, with undetermined worldwide incidence. ${ }^{4,5}$ In the United States it is estimated 3 cases per 100,000 people, and in the United Kingdom, 109 cases per million inhabitants. ${ }^{2,4}$ It is characterized by necrotizing granulomatous inflammation, primarily of kidney, upper and lower respiratory tract. ${ }^{4,5}$

Davies, in 1982, and Van der Woude, in 1985, showed anti-neutrophil cytoplasmic antibodies of cytoplasmic pattern (C-ANCA), in GP, with a specificity of $99.3 \%$ for the disease. ${ }^{5}$ The present study consists of a GP case report, highlighting its skin and systemic involvement, and its new nomenclature.

\section{CASE REPORT}

Woman, 18 years old, Caucasian, coming from Ceilândia (DF), with tumor on the left side of face and on right lower limb, which progressed to ulceration associated with ptosis of the left eyelid, bilateral epistaxis, purulent otorrhea in the left ear, palatal ulcer, anasarca and oliguria (Figures 1 and 2). Personal history: asthma since the age of eight. Physical examination: good general condition, pale; palate with painful ulceration in healing phase, ptosis of the left eyelid and two ulcers with infiltrative borders of $2 \mathrm{~cm}$ and $3 \mathrm{~cm}$, clean background, on left zygomatic area; wheezing at lung bases; extremity with edema and ulcer of $5 \mathrm{~cm}$ located in the right leg.

Imaging tests: chest $\mathrm{X}$-ray with mixed standard condensation foci at left lung base; cranial x-ray showing frontal sinus with increased volume, hyper transparent image in frontal region; sinus radiography with opacification and fluid levels in maxillary sinuses; cranial tomography with focal area of edema in the left frontal lobe compatible with cerebritis, infec-

Received on 15.02.2014

Approved by the Advisory Board and accepted for publication on 18.08.2014

Study performed at Hospital Regional da Asa Norte (HRAN) - Brasília (DF), Brazil.

Financial Support: None.

Conflict of Interest: None.

Universidade Federal de Mato Grosso do Sul (UFMS) - Campo Grande (MS), Brazil

Private clinic - Brasília (DF), Brazil.

Hospital Regional da Asa Norte (HRAN) - Brasília (DF), Brazil.

(C2015 by Anais Brasileiros de Dermatologia 


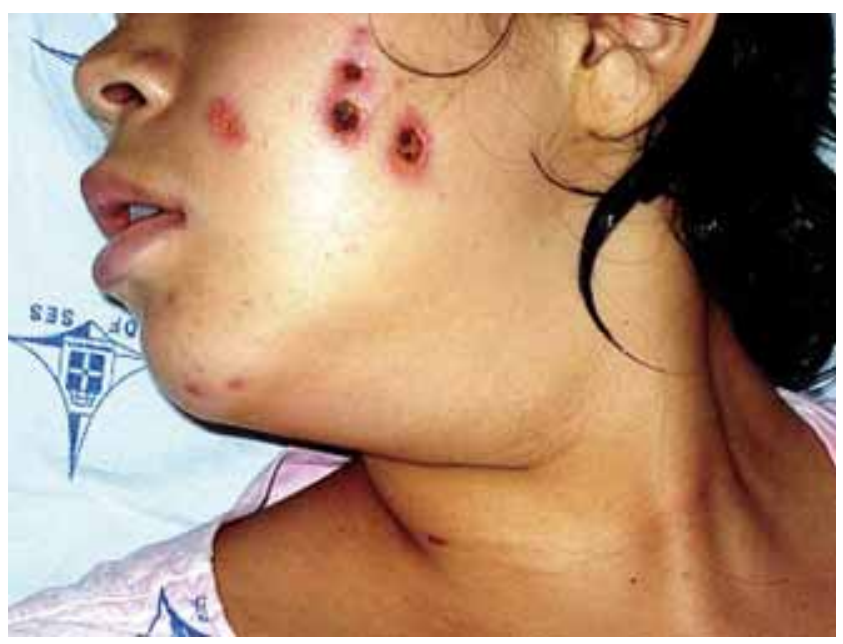

FIGURE 1: Ulcerative crusty lesions on the left side of the face

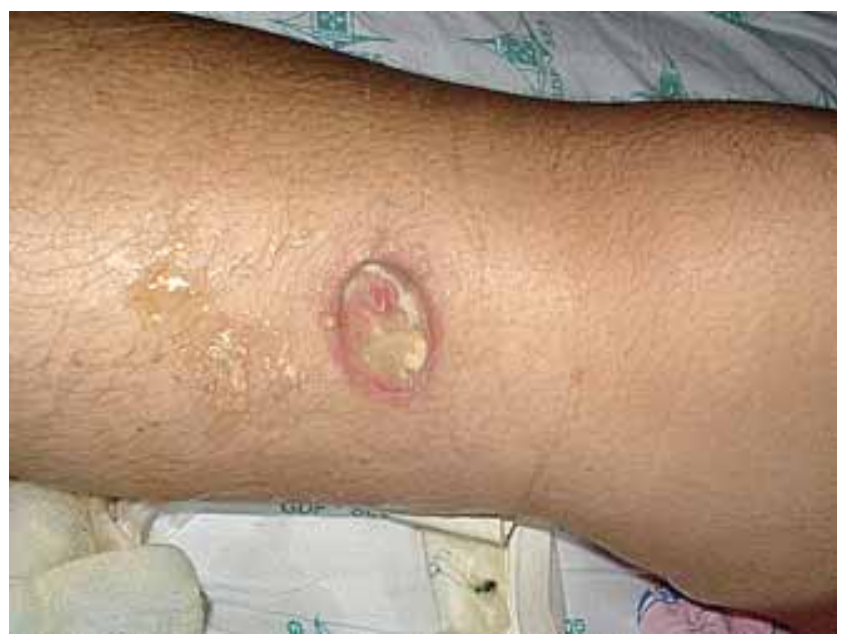

FIgURE 2: Fibrin-covered ulcer in the right lower limb

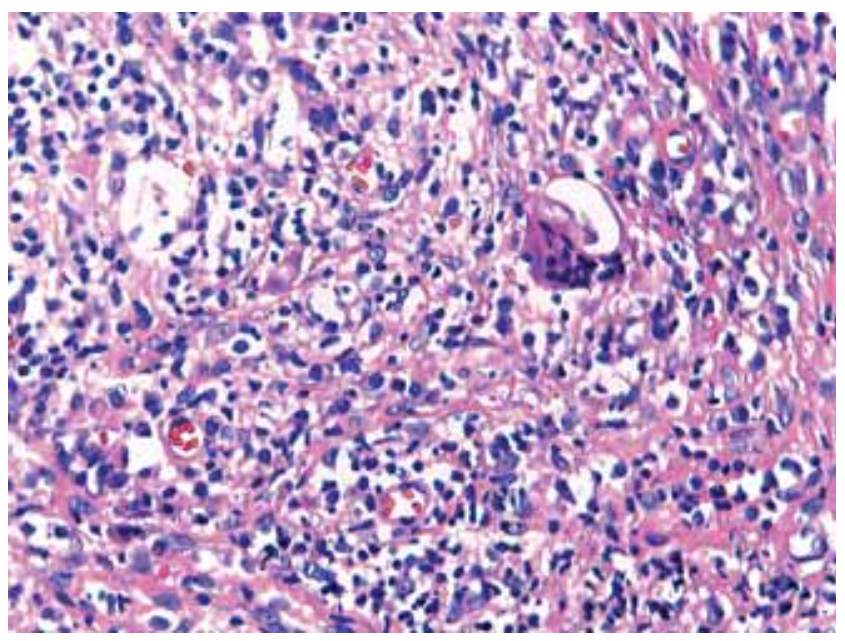

Figure 3: Anatomopathological examination of skin ulcer biopsy showing infiltrate, loose granulomas in the dermis, with multinucleated giant cells (40x) tious subdural collection and mastoiditis; abdominal ultrasound showing kidneys with corticomedullary demarcation poorly defined, increased cortical echogenicity, suggestive of parenchymal nephropathy.

Renal anatomopathological examination of clusters with increasing cell, fibrinoid necrosis foci, partial sclerosis of glomeruli and immunofluorescence with no deposits of immunoglobulins, complement fraction and fibrinogen, compatible with related standard c-ANCA.

Laboratory tests showed leukocytosis with neutrophilia of 89\% and C-ANCA 1:20. Anatomopathological examination of skin ulcer biopsy showed loose granulomatous infiltrate in the dermis, with multinucleate cells (Figure 3). After confirmation of the diagnosis of GP, it was started the pulse therapy with methylprednisolone $0.5 \mathrm{~g} /$ day for 5 days and maintenance prednisone at initial dose of $1 \mathrm{mg} / \mathrm{kg} /$ day (gradually reduced) and cyclophosphamide $2 \mathrm{mg} / \mathrm{kg} /$ day. Patient showed improvement of renal involvement, with a decrease in anasarca, serum creatinine, urea and upper respiratory symptoms, as well as accelerated healing of skin ulcers.

\section{DISAUSSION}

Classified as necrotizing granulomatous vasculitis of small and medium vessels, granulomatosis with polyangiitis (GP) is a rare multisystem disease. ${ }^{5}$ Presence of its triad - necrotizing granulomatous inflammation of the respiratory tract, cutaneous necrotizing vasculitis and glomerulonephritis - observed in our case guides the diagnosis, however these clinical manifestations may not occur simultaneously. ${ }^{1,2}$

Since 2013, due to the recommendations of the American College of Rheumatology (ACR), the American Society of Nephrology (ASN) and the European League Against Rheumatism (EULAR), a new Chapel Hill Consensus Conference (CCHC2012) updated the classification of Wegener's granulomatosis to granulomatosis with polyangiitis. The main purpose of this modification is to optimize the official system of classification of vasculitis in order to suggest more identifiable criteria for classification and diagnosis, thus avoiding eponyms. ${ }^{3}$

The involvement of the upper respiratory tract occurs in $50-80 \%$ of cases, and mainly in the form of chronic sinusitis. ${ }^{5}$ Studies show that skin manifestations may appear in $16 \%$ to $77 \%$ of cases and with varied presentations. ${ }^{1,2,4,6}$ Papulonecrotic lesions represent the most common injuries and they occur mainly in the lower limbs. ${ }^{2,6}$ Involvement of skin and mucosa, alone, feature a rare variant called localized granulomatosis. ${ }^{7}$

Renal vasculitis, necrotizing and granulomatous, happens in less than $50 \%$ of cases of GP. These 
vasculitis are late and don't occur in the limited form of the disease. The most frequently observed renal damage ( $75 \%$ to $80 \%$ of patients), though not decisive in GP, is the focal and segmental necrotizing glomerulonephritis and it may, in some cases, evolve into generalized glomerulonephritis. Vasculitis, in its granulomatous form in the renal tissue, is very rare. ${ }^{1,3,8}$

An important aspect in the diagnosis of GP is its antineutrophil cytoplasmic antibody profile. Originally these antibodies are associated with necrotizing vasculitis and they can be subdivided according to its stimulating antigen. 3,5 There are currently 2 main classifications for this class of antibodies: specific pattern for protein myeloperoxidase (MPO-ANCA) of perinuclear presentation ( $\mathrm{p}$-ANCA) and the specific pattern for proteinase 3 (PR3-ANCA) of cytoplasmic display (c-ANCA). ${ }^{3}$ The c-ANCA standard is the marker in GP and it was shown in laboratory tests of our case with a rate of 1:20.

Early treatment of remission induction is crucial to reverse the renal damage, and it is performed in $40 \%$ of cases within the first 3 months of symptoms, relying on the use of corticosteroids and cyclophospha- mide. ${ }^{1,2,5}$ Before introduction of cyclophosphamide, patients' outcome was invariably fatal, with a mean survival rate of 5 months and mortality rate of $82 \%$ in one year, reaching $90 \%$ in 2 years of the disease. Using this association, Mc Donald and Remee reviewed 411 treated cases, and observed a mean survival rate of $75 \%$ in 5.8 years. ${ }^{9}$ Currently, hopes are directed towards immunobiological agents. Among them, the most studied is rituximab, which found a place in the current EULAR recommendations as an alternative drug for refractory disease, being used at a dose of $375 \mathrm{mg} / \mathrm{m}^{2} /$ week for 4 weeks. ${ }^{10}$ Another alternative in the treatment of remission is methotrexate $15-25 \mathrm{mg} /$ week combined with folic acid. Maintenance can be done with azathioprine $2 \mathrm{mg} / \mathrm{kg} /$ day; leflunomide 20-30 mg/day or rituximab $1 \mathrm{~g}$ IV every 6 months for 2 years. ${ }^{10}$

In the presented case, pulse corticosteroids therapy was the chosen treatment, showing clinical and laboratorial remission, but cyclophosphamide was not administered in the form of pulse therapy due to a suspicion of pulmonary infection, which would worsen the clinical condition.

\section{REFERENCES}

1. Cox NH, Jorizzo JL, Bourke JF, Savage COS. Vasculitis, neutrophilic dermatoses and related disorders. In: Burns T, Breathnach S, Cox N, Griffiths C, editors. Rook's textbook of dermatology. London: Wiley Blackwell; 2010. p. 2417-19.

2. Chung L, Kea B, Fiorentino D. Cutaneous vasculitis. In: Bolognia J, Jorizzo J, Rapini R, and editors. Dermatology. New York: Elsevier, 2008. p.360-61.

3. Jennette JC, Falk RJ, Bacon PA, Basu N, Cid MC, Ferrario F, et al. 2012 Revised International Chapel Hill Consensus Conference Nomenclature of Vasculitides. Arthritis Rheum. 2013;65:1-11.

4. Taborda P, Taborda V. Granulomatose de Wegener. An Bras Dermatol. 1998;73:135-41

5. Brandt HR, Arnone M, Valente NY, Sotto MN, Criado PR. Medium and large vessel vasculitis. An Bras Dermatol. 2009;84:55-67.

6. Emedicine.Medscape.com [Internet]. Dermatologic manifestations of Wegener granulomatosis, Inc.; c2011 [updated 2013 0ct 23; cited 2014 Jan 29]. Available from: http://emedicine.medscape.com/article/1085290.

7. Fernandes NC, Cardoso ICL, Serpa SS, Rettore FC, Macieira J. Granulomatose de Wegener localizada: relato de caso. An Bras Dermatol. 1996;71:41-4.

8. Fernandes NC, Castilho M, Paes C, Macieira J. Granulomatose de Wegener localizada com manifestação ocular: relato de caso. An Bras Dermatol. 1998;73:107-10

9. Dey A, Arunabha DC, Sudipta P, Susmita K, Mita S. A young lady presented with limited pulmonary Weneger's Granulomatosis. Lung India. 2008;25:168-71.

10. Lutalo PM, D'Cruz DP. Diagnosis and classifcation of granulomatosis with polyangiitis (aka Wegener's granulomatosis). J Autoimmun. 2014;48-49:94-8.

\author{
M AILING ADDRESS: \\ A lexandre M oretti de Lima \\ 2165, D outor A rthur Jorge Street, A pt 601 \\ $M$ onte Castelo \\ 79010210 - Campo Grande - M S \\ Brazil \\ Email: morettilima@yahoo.com.br
}

H ow to cite this article: Lima AM, Torraca PFS, Rocha SP, Santiago CMR, Paes-Ferraz FHR. Granulomatosis with polyangiitis, a new nomenclature for Wegener's Granulomatosis - case report. . An Bras Dermatol. 2015;90 (3 Suppl 1):S101-3. 